At $x$-ray examination the chip fractures were best seen in the lateral and were invisible in the antero-posterior view. From the lateral it was not always easy to say whether the fragment had come from the dorsum of the os triquetrum or of the lunate; the oblique view, which is most important, showed the site of fracture in every case. This point was specially studied in view of the high figure $(59$ out of 1,106$)$ for avulsion fractures of the posterior process of the lunate in Schnek's series

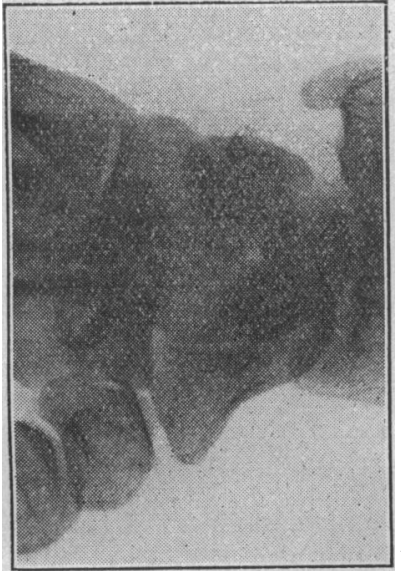

FIG. 1.-Pte. A.: Oblique view.

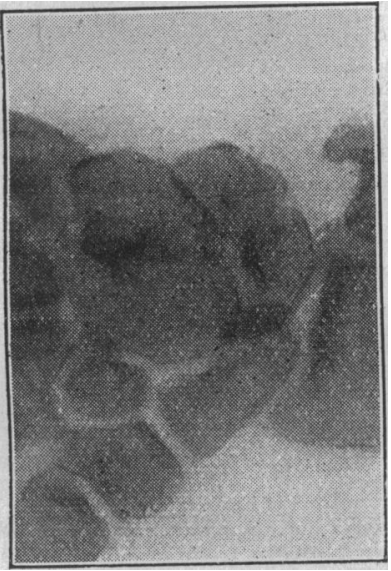

FIG. 3.-Pte. B.: Oblique view.

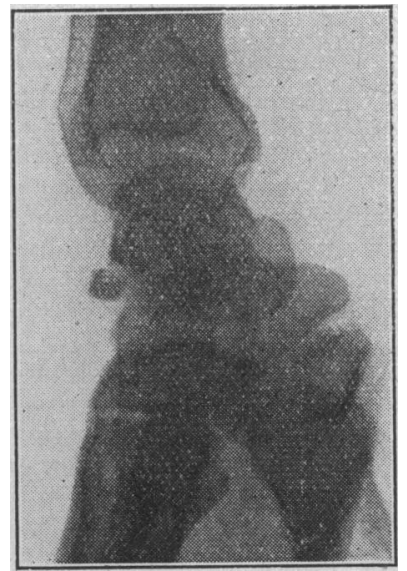

FIG. 2.-Pte. A.: Lateral view.

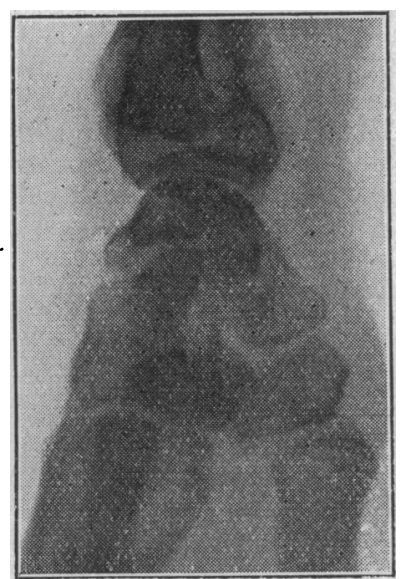

Fig. 4.-Pte. B.: Lateral view. as quoted by Böhler (1935). In the lateral view they varied from a minute flake to an oval fragment $4 \mathrm{~mm}$. in greatest diameter. In the two men with ulnar collateral ligament damage the fragment had been pulled proximally; of the remainder it lay over its bed in 3 and had been pushed distally in 5 . In no case were there any radiating cracks or fissures through the rest of the bone. The accompanying radiographs show the largest and the smallest fragments.

\section{Treatment and Results}

No attempt was made to reduce any displacement, which was never pronounced. The one complete fracture was immobilized in plaster-of-Paris for 15 weeks before union showed radiologically. The patient returned to full duty 4 weeks later. Eleven months after the injury the wrist was normal except for slight tenderness in the triquetral area.

The two avulsion fractures were also immobilized in plaster one for 4 weeks, the other for 9 weeks; these men were fit for all duties respectively 7 and 10 weeks from the injury. Nearly a year later they were both trouble-free, but one has limited flexion and very occasionally local pain; in his case $x$-ray examination at 6 months showed union incomplete, but at 12 months union had taken place.

With the exception of one man with a severe sprain put in plaster recently and still under treatment, the remainder ( 7 cases) were treated with elastoplast strapping only, and were fit for full duty in 1 to 28 days, the average time being 10 days. They have been "followed up" for periods varying from 2 to 12 months. Of the 7,4 are now normal in every way, one is normal except for slight limitation of flexion, and the other 2 suffer no inconvenience but still get slight pain on forced dorsiflexion. Radiographs show union to have taken place in all of them, although in some it was slow and still appears to be incomplete.

\section{Conclusions}

With such a small series it is impossible to draw wide conclusions, but the figures agree with those of Greening in showing that the fracture is more common than was formerly supposed. It is usually due to forcible dorsiflexion and ulnar deviation of the wrist, frequently the result of a backward fall on the outstretched hand. In $x$-ray diagnosis the oblique view shares importance with the lateral, and the chip of bone appears to be pushed off more often than pulled off. In the former the prognosis is excellent and recovery very rapid with minimai treatment ; although bony union may be delayed, immobilization does not appear to be necessary. The avulsion fractures, however, involving as they do damage to the ulnar collateral ligament, are more serious injuries and require longer treatment. It was a little surprising that the one complete fracture took so long to unite when immobilization was carefully maintained in a patient who had been using his hand to the full: Slight symptoms may persist for many months, but they do not interfere with the activities of the patient.

My thanks are dứe to Colonel J. R. N. Warburton, M.C., A.M.S., and to Colonel W. A. Jackman, A.M.S., for permission to publish these cases, and to Major W. N. Bıown, R.A.M.C., for his unfailing patience and excellent radiographs.

REFERENCES

Böhler, L. (1935). Treatment of Fractures, 4th English ed., translated by E. W Hey Groves, p. 253, Wright, Bristol.

Greening, W. P. (1942). British Medical Journal, 1, 221.

\section{Medical Memoranda}

\section{Pneumococcal Meningitis successfully treated with Sulphapyridine}

The following case, in which the chief features were the sudden onset and the rapidity of cure with sulphapyridine, is reported in order to draw attention to the possibility of lowering the mortality rate of pneumococcal meningitis.

\section{CASE REPORT}

An unmarried woman aged 21 was admitted to hospital at 11 a.m. on Feb. 17, 1940. On Feb. 15 she had not felt very well, and on the 16th had sent for her doctor, who diagnosed influenza. Some spots were then present on her arms and legs and she also complained of diplopia. At $3 \mathrm{a} . \mathrm{m}$. on the $17 \mathrm{th}$ she was very restless and started getting out of bed. She vomited 3 times, and by 5 a.m. was definitely unconscious.

On admission the patient was found to be comatose but very restless. Her head was retracted and her knees and hips flexed. She was lying on her side and giving out occasional meningeal cries. There were spots of an erythematous nature on her legs, and she was incontinent of urine and faeces. According to her mother she had not passed urine for 12 hours It was difificult to examine her very thoroughly, as she was so restless, but there was definite evidence of squint and ptosis of both eyelids, the left being more marked than the right. Kernig's and Brudzinski's signs were positive, Babinski's sign was flexor, and the abdominal reflexes were absent. The only abnormal finding in her. chest was evidence of slight consolidation at the left base. Her tongue was furred.

Under general anaesthesia $12 \mathrm{c.cm}$. of soluble sulphapyridine (equivalent to $4 \mathrm{~g}$. of the drug) was injected intramuscularly. Lumbar puncture was performed, and turbid fluid ran out under considerable pressure, too high to measure with a manometer. A deposit soon settled at the bottom of the $40 \mathrm{c} . \mathrm{cm}$. of cerebrospinal fluid that was taken, and from this deposit a slide was made which demonstrated extracellular pneumococci. There were 25,000 cells per c.mm., mostly polymorphs; with occasional red cells and macrophages; protein, $0.5 \mathrm{~g}$. \% ; sugar, trace only; chlorides, $725 \mathrm{mg}$. per $100 \mathrm{c.cm}$. Urine showed albumin + , sugar + , and acetone + ; its specific gravity was 1020 . By 9 p.m. the patient was notably improved. Whereas 
previously she had been quite unconscious, she now recognized her doctor and was able to answer questions. A further injection of $12 \mathrm{c.cm}$. of soluble sulphapyridine was given and pot. brom. $30 \mathrm{gr}$. and chloral $15 \mathrm{gr}$. were administered by mouth.

Feb. 18.- The patient had passed a fair night, but was still very restless. She had drunk about $35 \mathrm{oz}$. of fluid since admission and had been incontinent of urine and faeces. She now knew where she was. Her colour, which had been pale and somewhat cyanosed, was improved. The pulse was good and the blood pressure $80 / 50$. Kernig's sign was positive ; Brudzin-

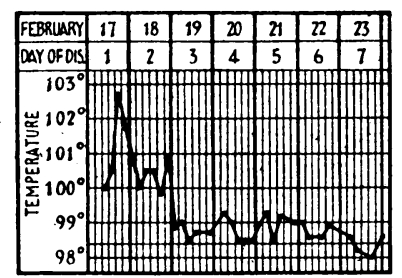

ski's and Babinski's signs were negative. The head was still retracted, and there was still marked squint and ptosis. Slight papilloedema of both disks was noted. The white blood cells numbered 20,000 per c.mm. $-76 \%$ polymorphs, $22 \%$ leucocytes. The urine was normal. Lumbar puncture was performed under general anaesthesia, $40 \mathrm{c.cm}$. of fluid being run out under pressure too high to read with a manometer. The fluid was considerably less turbid, and intracellular pneumococci were demonstrated. An injection of $6 \mathrm{c.cm}$. of soluble sulphapyridine was given intramuscularly in the morning and again in the evening.

Feb. 19.-The patient's condition was still improving. She had no headache, but complained of stiffness in her neck. She still rolled about a great deal in bed, and kept her knees well drawn up. Lumbar puncture was performed under general anaesthesia, $25 \mathrm{c.cm}$. of less turbid fluid being drawn off under pressure still too high to read with an ordinary glass manometer. 500 red cells and 500 white cells were found per c.mm.; protein, $0.08 \mathrm{~g}$. $\%$; chlorides, $760 \mathrm{mg}$. per $100 \mathrm{c.cm}$.; sugar positive ; Nonne-Apelt reaction, slightly positive. $6 \mathrm{c.cm}$. of soluble sulphapyridine was administered intramuscularly in the morning and again in the evening. Altogether $48 \mathrm{c.cm}$. of the soluble substance was administered in 3 days. The fall in temperature over this period can be seen from the Chart. i

$F e b$. 20.-Lumbar puncture was performed under local anaesthesia and the fluid ran out at the rate of about 1 drop in 3 seconds, now being clear. The general condition of the patient was much improved, but Kernig's sign, head retraction, and ptosis of both eyelids, as well as diplopia, were still present The squint was less marked. During the 24 hours 2 g. of sulphapyridine was administered by mouth.

$F e b$. 21.-The findings were similar to those of the previous day, but lumbar puncture was not performed. The blood pressure was $120 / 70.2 \mathrm{~g}$. of sulphapyridine was given by mouth.

Feb. 22.-A blood count showed 6.400 leucocytes per c.mm. There was no head retraction, Kernig's sign was negative, and slight ptosis and slight "blurring" of vision were still present.

Feb. 23.-Sight quite normal. No ptosis. Felt quite well.

May 1, 1942.--It has been ascertained by one of us (E. W. M. W.) that this patient has remained quite well ; there have been no sequelae, and it is interesting to note that she is now serving with the Forces.

We wish to thank Dr. C. M. Hinds Howell for his kind advice throughout this case.

\section{E. W. Meurig Williams, M.B., B.Ch., B.Sc., Elliot PhilipP, M.R.C.S., L.R.C.P., Late House-surgeon.}

Harrow and Wealdstone Hospital.

In a bronchoscopic investigation of asthmatic children E. L. van Loon and S. Diamond (Amer. J. Dis. Child., 1942, 63, 217) found no support for the theory of a bronchospastic origin of the wheezing and dyspnoea. Admitting that the bronchoscopist cannot explore the small peripheral bronchi and bronchioles, they agree with Jackson that spasmodic contraction of such small bronchi is hardly compatible with the production of a wheeze audible at the open mouth. In 100 asthmatic children non-specific inflammatory changes were observed in 91 , and in 20 in whom bronchography was done 5 were found to have bronchiectasis. The only constant feature found in children examined during an attack was the presence of a thick viscid secretion within the bronchial lumen.

\section{Reviews}

\section{PULMONARY TUBERCULOSIS}

Pulmonary Tuberculosis and its Treatment. By Hans Jacob Ustvedt, M.D. Translated by A. L. Jacobs, M.R.C.P. With a foreword by W. D. W Brooks, D.M., F.R.C.P. (Pp. 252. 25s.) London: John Bale Medical Pubications, Ltd. 1942

Dr. H. J. Ustvedt has written an extremely interesting volume on pulmonary tuberculosis, and, especially on the side of treatment, has gathered together a great many facts and observations which are well placed in the making of a readable book. He has evidently studied tuberculosis with a critical eye to the types prevalent at different ages and to the varying modes in which the disease tends to express itself in persons of means on the one hand and those subjected to want on the other. $\mathrm{He}$ is also prepared to see in immunity and resistance two of the principal factors on which the defence of the body depends. "In tuberculosis," he says, " as with other infections, immunity is the specific increase in resisting power which the organism acquires as a result of the infection. ... Resistance is that power of withstanding the attack of the tubercle bacillus which the organism possesses apart from the effects of the infection itself." This distinction has long been made in England, though what Ustvedt calls "resistance" is usually spoken of as "natural immunity." He quotes the findings of Heimbeck and of Scheel, already familiar to tuberculosis specialists in this country, on the B.C.G. vaccination of tuberculin-negative probationer nurses at Ullevaal, by which they were brought up to the same level as the originally positive group-a finding which strongly suggests to him "that it is not only resistance but also immunity which is responsible for the low morbidity among the positive reactors." He notes, too, the marked effect of environment on the continued latency or the progressive development of the disease, citing malnutrition, poverty, occasionally pregnancy, strain, and other human trials as calculated to lead up the implanted infection to the clinical level.

Speaking of silicosis and the inhalation of dust, he remarks that " if we are to show a causative relation between a single factor associated with a particular occupation and the incidence of tuberculosis, all the other factors enumerated above "-here he means the environmental factors which we have mentioned - "must be taken into account. If this . is done it becomes doubtful how far silicosis in itself really predisposes towards the development of tuberculous changes." We can only suppose that the author's acquaintance with silicosis is based on a much smaller experience than his knowledge of tuberculosis. As to the symptomatology of phthisis, his remarks are exceedingly valuable and should be read with interest and profit by all students of the disease. There is a good description of tuberculous meningitis-though it is assumed that this is nearly always connected with an attack of miliary tuberculosis-and there is no mention of tuberculoma of the brain. The author might well acquaint himself with the work of Arnold Rice Rich of the Johns Hopkins Hospital and of others on this subject.

In the book under review the question of treatment practically resolves itself into a consideration of collapse therapy. This concentration on what is perhaps the anly type of treatment that counts at present is right and proper in a book intended to be a modern expression of the tuberculosis problem. The author very correctly condemns " high-pigeve pneumothorax treatment," but we cannot agree with hin the immobilization of the lung is almost entirely illusory" and that "the effect of treatment is at all events not related to this factor." Nobody believes that the lung is completely immobilized, but it is relatively immobilized by the cushion of air which prevents the constant drag of the expanding and contracting thoracic wall, and this must go far to explain the good results of pneumothorax therapy. We quite agree with him that this treatment really amounts to "a mechanical treatment of cavitation"; in fact, we are of the opinion that nearly every secondary tuberculous affection of the lung is accompanied by cavity formation, whether the cavities show in the radiograph or not. Ustvedt believes in bilateral pneumothorax, and devotes a considerable amount of space to this excellent 